\title{
IDENTIFICATION OF UNBALANCED FORCES AND FOUNDATION PARAMETERS OF ROTATING MACHINES FROM VIBRATION MEASUREMENTS
}

\author{
N.G. Nalitolela \\ Department of Mechanical and Industrial Engineering, University of Dar es Salaam, \\ P.O. Box 35131 Dar es Salaam.Email: noel@uccmail.co.tz
}

\begin{abstract}
A technique is described to use measured vibration data of a rotating machine and its foundation to identify unbalanced forces, stiffness and damping parameters of the mountings, and the parameters of the foundation. It is based on an idealisation treating the rotor, the machine structure and the foundation as rigid masses supported by springs and dampers. Operational vibration data of the machine and its foundation before and after the rotating unbalanced forces are perturbed by adding unbalanced mass to the rotor are used in the identification procedure. Once the parameters are identified, dynamic forces transmitted to the foundation can be estimated. The technique is demonstrated using simulated example for a machine with a two bearings rotor.
\end{abstract}

[Keywords: Identification, unbalanced forces, rotating machines, vibration, foundation]

\subsection{INTRODUCTION}

Rotating machines are liable to shaking as a result of excitations due to unbalanced dynamic forces and moments generated within the machines. These unbalanced excitations ultimately find their way to the foundations or supporting structures. With unfavourable combination of operating speed, stiffness and damping properties of the mounting system, amplification of the transmitted forces may occur. The transmissibility of large dynamic force to the foundation is always an issue of concern due to possible structural failure of the foundation or disturbing vibrations being transmitted to nearby structures or occupants. It is known, however, that balancing may not be perfect and in some cases it is not practical to balance the forces fully. Furthermore, isolation systems are usually designed on the assumption of a fixed foundation, whereas in reality a foundation may be flexible and its dynamic behaviour unknown. Apart from the need to design machinery to operate within acceptable limits, accurate dynamic modelling of machine systems is important. Dynamic models may be used to facilitate diagnosis of operational difficulties. The analysis of vibration behaviour of turbo-machinery, for example, is a topic of great importance in most process industries and particularly in power generation. A number of authors have addressed this problem (Lees (1988), Zanetta (1992), Odiara and Ewins (1992), Lees and Friswell (1996), Sinha et al (2002)) and the conclusion is that the supporting structure of a large turbine presents a significant problem, having a significant effect on the dynamic behaviour of the machine. The previous researchers have attempted to establish foundation's dynamic properties by extracting information from the response of the foundation due to a known unbalance on the rotor. The key to the problem was the derivation of forces exerted on the foundations at the bearings. Lees and Friswell (1996), and Sinha et al (2002) use vibration measurements of the bearing pedestals to derive the forces transmitted to the foundation. Their methods assume the bearing stiffness is known and the foundation is modelled as a mass less spring. This paper presents an alternative technique which does not assume prior knowledge of the rotor unbalance or bearing stiffness and the foundation is modelled as a mass-spring-damper system. The vibration response of the machine and the foundation before and after the unbalanced forces are perturbed by adding unbalanced mass to the rotor are used in the identification. Unbalanced forces, stiffness and damping properties of the 
machine mounting system as well as mass, stiffness and damping properties of the foundation are identified. The technique is demonstrated using numerical example on a machine with a two bearings rotor.

\subsection{THEORY}

\subsection{MATHEMATICAL MODEL}

Consider a rotating machine with a 2 bearings rotor as shown in Fig. 1. The rotor, treated as rigid, is supported by two bearings of stiffness $k_{b 1}$ and $k_{b 2}$ and damping coefficients $c_{b 1}$ and $c_{b 2}$ respectively. The rotor is of mass $m_{r}$ and mass moment of inertia $I_{r}$ about the centre of gravity of the rotor and in the vertical plane shown. The machine structure is also treated as rigid and is mounted to the foundation through mounting stiffness $k_{s 1}$ and $k_{s 2}$ and damping coefficients $c_{s 1}$ and $c_{s 2}$. The machine structure is of mass $m$ and mass moment of inertia $I$. about its centre of gravity. The foundation is modelled as a mass-spring-damper system with respective parameters $m_{f}, k_{f}$ and $c_{f}$ being the same under both mountings. The system possesses 6 degrees-of-freedom (DOF) labelled as $q_{1}$ to $\mathrm{q}_{6}$.

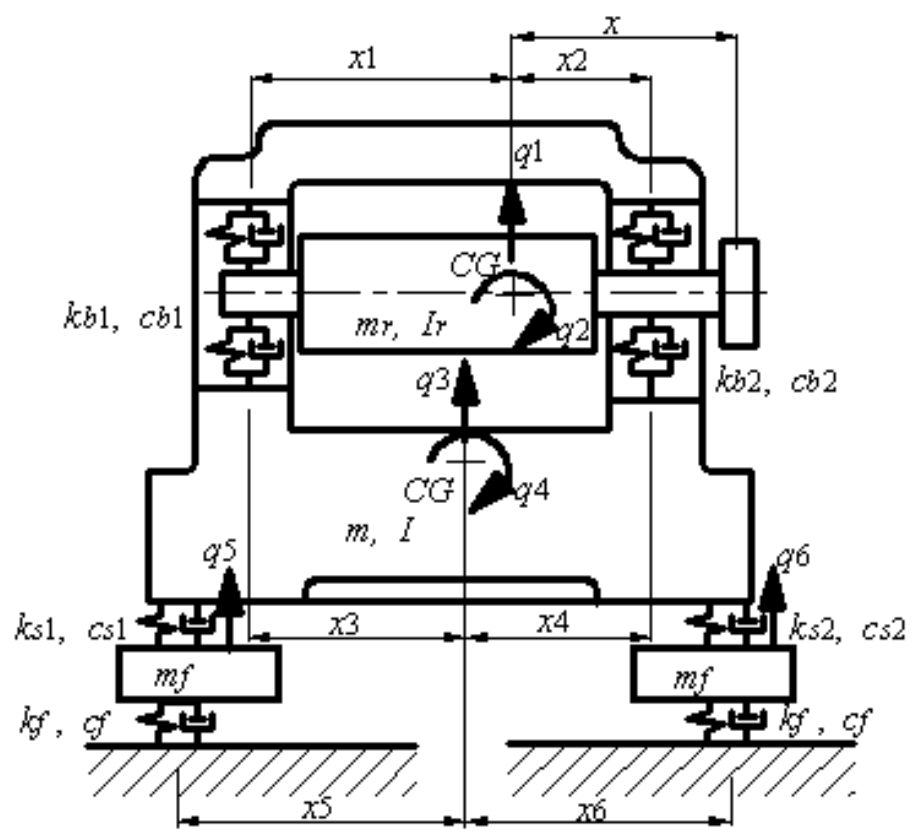

Fig. 1: Model of a Rotating Machine with a Two Bearings Rotor

Let the rotor unbalance be represented by unbalance force $F_{u}(t)$ and moment $M_{u}(t)$ at its centre of gravity. These unknown unbalanced loads result in bearing forces $F_{b 1}(t)$ and $F_{b 2}(t)$ being transmitted from the rotor to the machine structure through the two rotor bearings. Fig. 2(a) shows the model of the rotor and the machine structure, with the rotor isolated from the machine, depicting the free body diagram. Fig. 2(b) is an equivalent model of the machine structure where the bearing loads are represented by an equivalent unbalanced force $F_{B}(t)$ and moment $M_{B}(t)$. Distances $x_{1}, x_{2}$ are horizontal distances to the bearings from the rotor centre of gravity whereas $x_{3}$ and $x_{4}$ are horizontal distances to the bearings from the centre of gravity of the machine structure. Distances $x_{5}$ and $x_{6}$ are horizontal distances of the machine mountings to the centre of gravity of the machine. 
(b)
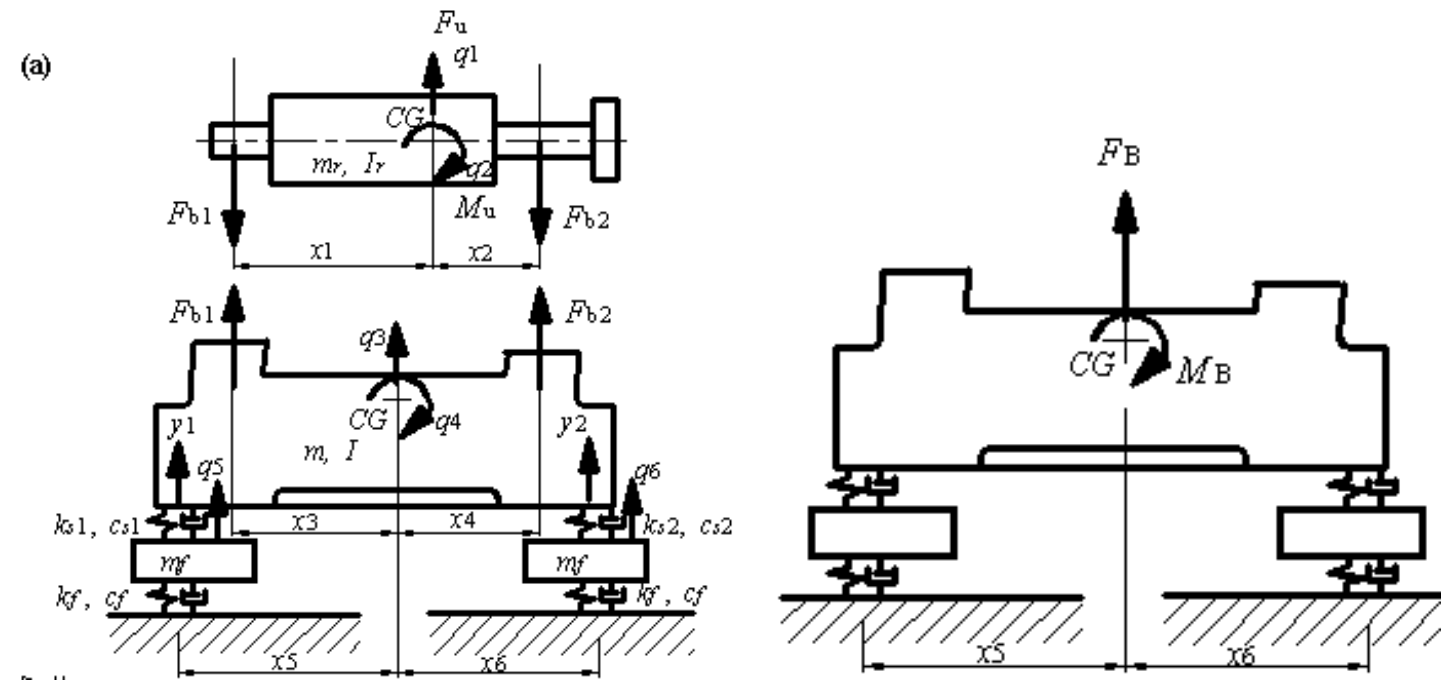

Fig. 2: (a) Free Body Diagrams (b) Equivalent loading on Machine Structure

Applying Newton's equation of motion to the rotor in the translational degree-of-freedom results in the following:

$$
\begin{aligned}
& F_{u}(t)-F_{b 1}(t)-F_{b 2}(t)=m_{r} \ddot{q}_{1}(t) \\
& F_{b 1}(t)+F_{b 2}(t)=F_{u}(t)-m_{r} \ddot{q}_{1}(t)
\end{aligned}
$$

Likewise, Newton's equation of motion applied to the machine structure in the translational degreeof-freedom results in:

$$
\begin{array}{r}
F_{b 1}(t)+F_{b 2}(t)-k_{s 1}\left[y_{1}(t)-q_{5}(t)\right]-c_{s 1}\left[\dot{y}_{1}(t)-\dot{q}_{5}(t)\right]-k_{s 2}\left[y_{2}(t)-q_{6}(t)\right]-c_{s 2}\left[\dot{y}_{2}(t)-\dot{q}_{6}(t)\right] \\
=m \ddot{q}_{3}(t)
\end{array}
$$

Replacing $F_{b 1}(t)+F_{b 2}(t)$ in eq. (2) by eq. (1) and re-arranging results in:

$$
\begin{aligned}
k_{s 1}\left[y_{1}(t)-q_{5}(t)\right]+c_{s 1}\left[\dot{y}_{1}(t)-\dot{q}_{5}(t)\right]+ & k_{s 2}\left[y_{2}(t)-q_{6}(t)\right]+c_{s 2}\left[\dot{y}_{2}(t)-\dot{q}_{6}(t)\right]-F_{u}(t) \\
& =-m_{r} \ddot{q}_{1}(t)-m \ddot{q}_{3}(t)
\end{aligned}
$$

Let the unbalanced force and moment be harmonic. The resulting vibrations will also be harmonic. Therefore

$$
\begin{array}{ll}
F_{u}(t)=\left|F_{u}\right| \cos \left(\omega t+\varphi_{f}\right)=\operatorname{Real}\left(F_{u} e^{j\left(\omega t+\varphi_{f}\right)}\right) & \\
M_{u}(t)=\left|M_{u}\right| \cos \left(\omega t+\varphi_{m}\right)=\operatorname{Real}\left(M_{u} e^{j\left(\omega t+\varphi_{m}\right)}\right) & \\
q_{i}(t)=\left|q_{i}\right| \cos \left(\omega t+\varphi_{i}\right)=\operatorname{Real}\left(q_{i} e^{j\left(\omega t+\varphi_{i}\right)}\right) & (\mathrm{i}=1 \ldots 6) \\
y_{i}(t)=\left|y_{i}\right| \cos \left(\omega t+\varphi_{i}\right)=\operatorname{Real}\left(y_{i} e^{j\left(\omega t+\varphi_{i}\right)}\right) & (\mathrm{i}=1 \ldots 2)
\end{array}
$$


In general, $F_{u}, M_{u}, q_{i}$ and $y_{i}$ are complex quantities with the phase angles referred from an arbitrary datum. In view of the above, eq. (3) can be transformed into the frequency domain as:

$$
\left(k_{s 1}+j \omega c_{s 1}\right)\left(y_{1}-q_{5}\right)+\left(k_{s 2}+j \omega c_{s 2}\right)\left(y_{2}-q_{6}\right)-F_{u}=\omega^{2} m_{r} q_{1}+\omega^{2} m q_{3}
$$

Newton's equation of motion applied to the foundation under the two supports results in the following two equations:

$$
\begin{aligned}
& -k_{f} q_{5}(t)-c_{f} \dot{y}_{5}(t)+k_{s 1}\left[y_{1}(t)-q_{5}(t)\right]+c_{s 1}\left[\dot{y}_{1}(t)-\dot{q}_{5}(t)\right]=m_{f} \ddot{q}_{5}(t) \\
& -k_{f} q_{6}(t)-c_{f} \dot{y}_{2}(t)+k_{s 2}\left[y_{2}(t)-q_{6}(t)\right]+c_{s 2}\left[\dot{y}_{2}(t)-\dot{q}_{6}(t)\right]=m_{f} \ddot{q}_{6}(t)
\end{aligned}
$$

Transforming them into the frequency domain in terms of complex displacements, and re-arranging, result in:

$$
-\omega^{2} m_{f} q_{5}+\left(k_{f}+j \omega c_{f}\right) q_{5}=\left(k_{s 1}+j \omega c_{s 1}\right)\left(y_{1}-q_{5}\right)
$$

and

$$
-\omega^{2} m_{f} q_{6}+\left(k_{f}+j \omega c_{f}\right) q_{6}=\left(k_{s 2}+j \omega c_{s 2}\right)\left(y_{2}-q_{6}\right)
$$

Now consider moment equilibrium of the rotor in the plane shown and about the centre of gravity of the machine structure.

$$
M_{u}(t)+\left(x_{3}-x_{1}\right) F_{u}(t)+x_{4} F_{b 2}(t)-x_{3} F_{b 1}(t)=I_{r} \ddot{q}_{2}(t)+\left(x_{3}-x_{1}\right) m_{r} \ddot{q}_{1}(t)
$$

Re-arranging:

$$
x_{3} F_{b 1}(t)-x_{4} F_{b 2}(t)=M_{u}(t)+\left(x_{3}-x_{1}\right) F_{u}(t)-I_{r} \ddot{q}_{2}(t)-\left(x_{3}-x_{1}\right) m_{r} \ddot{q}_{1}(t)
$$

Similarly, consider moment equilibrium of the machine structure in the plane shown and about its centre of gravity:

$$
\begin{array}{r}
x_{3} F_{b 1}(t)-x_{4} F_{b 2}(t)+k_{s 2}\left[y_{2}(t)-q_{6}(t)\right] x_{6}+c_{s 2}\left[\dot{y}_{2}(t)-\dot{q}_{6}(t)\right] x_{6}-k_{s 1}\left[y_{1}(t)-q_{5}(t)\right] x_{5} \\
-c_{s 1}\left[\dot{y}_{1}(t)-\dot{q}_{5}(t)\right] x_{5}=I \ddot{q}_{4}(t)
\end{array}
$$

Replacing $x_{3} F_{b 1}(t)-x_{4} F_{b 2}(t)$ in eq. (8) by eq. (7) results in:

$$
\begin{aligned}
M_{u}(t)+\left(x_{3}-x_{1}\right) F_{u}(t)+k_{s 2}[ & \left.y_{2}(t)-q_{6}(t)\right] x_{6}+c_{s 2}\left[\dot{y}_{2}(t)-\dot{q}_{6}(t)\right] x_{6}-k_{s 1}\left[y_{1}(t)-q_{5}(t)\right] x_{5} \\
& -c_{s 1}\left[\dot{y}_{1}(t)-\dot{q}_{5}(t)\right] x_{5}=I \ddot{q}_{4}(t)+I_{r} \ddot{q_{2}}(t)+\left(x_{3}-x_{1}\right) m_{r} \ddot{q}_{1}(t)
\end{aligned}
$$

Since the unbalanced force and moment as well as the resulting vibrations are harmonic, eq. (9) can be expressed in terms of complex quantities and on re-arranging results in:

$$
\begin{aligned}
-\left(k_{s 1}+j \omega c_{s 1}\right)\left(y_{1}-q_{5}\right) x_{5}+\left(k_{s 2}+j \omega c_{s 2}\right)\left(y_{2}-q_{6}\right) & x_{6}+\left(x_{3}-x_{1}\right) F_{u}+M_{u} \\
& =\omega^{2} m_{r} q_{1}\left(x_{1}-x_{3}\right)-\omega^{2} I_{r} q_{2}-\omega^{2} I q_{4}
\end{aligned}
$$


Now, eqs. (4) and (10) are the key translational and rotational equations of motion needed for the next stage of identification of unbalanced force, moment and mounting parameters. Eqs. (5) and (6) shall be used to identify foundation parameters once the mounting parameters are identified.

\subsection{IDENTIFICATION OF FORCES AND MOUNTING PARAMETERS}

Suppose we now perturb the unbalanced force by adding known unbalanced mass $\Delta m$ to the rotor and with this added mass, we measure new vibrations which we assign a subscript $p$ to indicate measurement on the perturbed system. Let $e$ denote the radial position vector to this added mass such that the increment in unbalanced force due to the added mass is $\omega^{2} \Delta m \times e$. Thus, for this perturbed case, eq. (4) becomes:

$$
\left(k_{s 1}+j \omega c_{s 1}\right)\left(y_{1 p}-q_{5 p}\right)+\left(k_{s 2}+j \omega c_{s 2}\right)\left(y_{2 p}-q_{6 p}\right)-F_{u}=\omega^{2} m_{r} q_{1 p}+\omega^{2} m q_{3 p}+\omega^{2} \Delta m \times e
$$

Let $x_{e}$ be the moment arm perpendicular distance of the line of action of the perturbing centrifugal force from the centre of gravity of the machine structure. The added mass will result in moment increment of $\omega^{2} \Delta m \times e x_{e}$ Therefore, moment equation, eq. (10), becomes:

$$
\begin{aligned}
& -\left(k_{s 1}+j \omega c_{s 1}\right)\left(y_{1 p}-q_{5 p}\right) x_{5}+\left(k_{s 2}+j \omega c_{s 2}\right)\left(y_{2 p}-q_{6 p}\right) x_{6}+\left(x_{3}-x_{1}\right) F_{u}+M_{u} \\
& =\omega^{2} m_{r} q_{1 p}\left(x_{1}-x_{3}\right)-\omega^{2} I_{r} q_{2 p}-\omega^{2} I q_{4 p}-\left(x_{3}-x_{1}\right) \omega^{2} \Delta m \times e-\omega^{2} \Delta m \times e x_{e}
\end{aligned}
$$

Equations (4), (10), (11) and (12) are combined into the following matrix equation:

$$
[\mathbf{Q}]\left\{\begin{array}{c}
k_{s 1}+j \omega c_{s 1} \\
k_{s 2}+j \omega c_{s 2} \\
F_{u} \\
M_{u}
\end{array}\right\}=\{\mathbf{b}\}
$$

where

$$
\begin{aligned}
& {[\mathbf{Q}]=\left[\begin{array}{llll}
\left(y_{1}-q_{5}\right) & \left(y_{2}-q_{6}\right) & -1 & 0 \\
-\left(y_{1}-q_{5}\right) x_{5} & \left(y_{2}-q_{6}\right) x_{6} & \left(x_{3}-x_{1}\right) & 1 \\
\left(y_{1 p}-q_{5 p}\right) & \left(y_{2 p}-q_{6 p}\right) & -1 & 0 \\
-\left(y_{1 p}-q_{5 p}\right) x_{5} & \left(y_{2 p}-q_{6 p}\right) x_{6} & \left(x_{3}-x_{1}\right) & 1
\end{array}\right]} \\
& \{\mathbf{b}\}=\left\{\begin{array}{c}
\omega^{2} m_{r} q_{1}+\omega^{2} m q_{3} \\
\omega^{2} m_{r} q_{1}\left(x_{1}-x_{3}\right)-\omega^{2} I_{r} q_{2}-\omega^{2} I q_{4} \\
\omega^{2} m_{r} q_{1 p}+\omega^{2} m q_{3 p}+\omega^{2} \Delta m \times e \\
\omega^{2} m_{r} q_{1 p}\left(x_{1}-x_{3}\right)-\omega^{2} I_{r} q_{2 p}-\omega^{2} I q_{4 p}-\left(x_{3}-x_{1}\right) \omega^{2} \Delta m \times e-\omega^{2} \Delta m \times e x_{e}
\end{array}\right\}
\end{aligned}
$$


We can perform more than one case of mass additions on the rotor and the corresponding vibrations used to build up $[\mathbf{Q}]$ and $\{b\}$ matrices. For a rectangular $[\mathbf{Q}]$ matrix, the unknown parameters are obtained by pseudo-inverse solution of eq. (13). Thus,

$$
\left\{\begin{array}{c}
k_{s 1}+j \omega c_{s 1} \\
k_{s 2}+j \omega c_{s 2} \\
F_{u} \\
M_{u}
\end{array}\right\}=\left[\mathbf{Q}^{\mathrm{T}} \mathbf{Q}\right]^{-1} \mathbf{Q}^{\mathrm{T}}\{\mathbf{b}\}
$$

\subsection{IDENTIFICATION OF FOUNDATION PARAMETERS}

Adding unbalanced mass to the rotor employed in section 2.1 cannot help us to solve for the foundation parameters in eqs. (5) and (6). Instead, after establishing mounting parameters $k_{s 1}, c_{s 1}, k_{s 2}$ and $c_{s 2}$ from eq. (14), the rotor is operated at a different speed, resulting in new vibrations. Let subscript $x$ be added to denote frequency and displacements corresponding to the new speed. At this new speed, eq. (5) becomes:

$$
-\omega_{x}{ }^{2} m_{f} q_{5 x}+\left(k_{f}+j \omega_{x} c_{f}\right) q_{5 x}=\left(k_{s 1}+j \omega_{x} c_{s 1}\right)\left(y_{1 x}-q_{5 x}\right)
$$

Multiplying eq. (5) by $\omega_{x}^{2} q_{5 x}$ and eq. (15) by $\omega^{2} q_{5}$ respectively, result in:

$$
\begin{aligned}
& -\omega_{x}{ }^{2} \omega^{2} m_{f} q_{5} q_{5 x}+\left(k_{f}+j \omega c_{f}\right) q_{5} \omega_{x}{ }^{2} q_{5 x}=\left(k_{s 1}+j \omega c_{s 1}\right)\left(y_{1}-q_{5}\right) \omega_{x}{ }^{2} q_{5 x} \\
& -\omega^{2} \omega_{x}{ }^{2} m_{f} q_{5 x} q_{5}+\left(k_{f}+j \omega_{x} c_{f}\right) q_{5 x} \omega^{2} q_{5}=\left(k_{s 1}+j \omega_{x} c_{s 1}\right)\left(y_{1 x}-q_{5 x}\right) \omega^{2} q_{5}
\end{aligned}
$$

Subtract eq. (16) from eq. (17) results in:

$$
k_{f}\left(\omega^{2}-\omega_{x}^{2}\right) q_{5} q_{5 x}+j c_{f}\left(\omega^{2} \omega_{x}-\omega_{x}^{2} \omega\right) q_{5} q_{5 x}=A_{1}+j B_{1}
$$

Where:

$$
A_{1}+j B_{1}=\left(k_{s 1}+j \omega_{x} c_{s 1}\right)\left(y_{1 x}-q_{5 x}\right) \omega^{2} q_{5}-\left(k_{s 1}+j \omega c_{s 1}\right)\left(y_{1}-q_{5}\right) \omega_{x}^{2} q_{5 x}
$$

Eq. (18) is transformed into two separate equations by equating the real parts as well as imaginary parts. Thus:

$$
\begin{aligned}
& \left(\omega^{2}-\omega_{x}{ }^{2}\right) k_{f} \operatorname{Real}\left(q_{5} q_{5 x}\right)-\left(\omega^{2} \omega_{x}-\omega_{x}{ }^{2} \omega\right) c_{f} \operatorname{Imag}\left(q_{5} q_{5 x}\right)=A_{1} \\
& \left(\omega^{2}-\omega_{x}{ }^{2}\right) k_{f} \operatorname{Imag}\left(q_{5} q_{5 x}\right)+\left(\omega^{2} \omega_{x}-\omega_{x}{ }^{2} \omega\right) c_{f} \operatorname{Real}\left(q_{5} q_{5 x}\right)=B_{1}
\end{aligned}
$$

Likewise, the other mounting support results in similar equations but based on vibrations $q_{6}$ and $q_{6 x}$ at rotor frequencies $\omega$ and $\omega_{x}$ respectively, and corresponding vector $A_{2}+j B_{2}$, i.e.

$$
\begin{aligned}
& \left(\omega^{2}-\omega_{x}{ }^{2}\right) k_{f} \operatorname{Real}\left(q_{6} q_{6 x}\right)-\left(\omega^{2} \omega_{x}-\omega_{x}{ }^{2} \omega\right) c_{f} \operatorname{Imag}\left(q_{6} q_{6 x}\right)=A_{2} \\
& \left(\omega^{2}-\omega_{x}{ }^{2}\right) k_{f} \operatorname{Imag}\left(q_{6} q_{6 x}\right)+\left(\omega^{2} \omega_{x}-\omega_{x}{ }^{2} \omega\right) c_{f} \operatorname{Real}\left(q_{6} q_{6 x}\right)=B_{2}
\end{aligned}
$$


Equations (19) to (22) may be used to solve for $k_{f}$ and $c_{f}$. However, before proceeding with the solution for $k_{f}$ and $c_{f}$, lets first consider $m_{f}$. Multiplying eqs. (5) and (15) by $q_{5 x}$ and $q_{5}$ respectively, result in:

$$
-\omega^{2} m_{f} q_{5} q_{5 x}+\left(k_{f}+j \omega c_{f}\right) q_{5} q_{5 x}=\left(k_{s 1}+j \omega c_{s 1}\right)\left(y_{1}-q_{5}\right) q_{5 x}
$$

and

$$
-\omega_{x}{ }^{2} m_{f} q_{5 x} q_{5}+\left(k_{f}+j \omega_{x} c_{f}\right) q_{5 x} q_{5}=\left(k_{s 1}+j \omega_{x} c_{s 1}\right)\left(y_{1 x}-q_{5 x}\right) q_{5}
$$

Subtracting eq. (23) from eq. (24) results in:

$$
\begin{aligned}
\left(\omega^{2}-\omega_{x}^{2}\right) m_{f} q_{5} q_{5 x}-j\left(\omega-\omega_{x}\right) c_{f} q_{5} q_{5 x}=k_{s 1}\left[\left(y_{1 x}-q_{5 x}\right) q_{5}-\left(y_{1}-q_{5}\right) q_{5 x}\right] & \\
& +j c_{s 1}\left[\left(y_{1 x}-q_{5 x}\right) \omega_{x} q_{5}-\left(y_{1}-q_{5}\right) \omega q_{5 x}\right]
\end{aligned}
$$

Or

$-j\left(\omega-\omega_{x}\right) c_{f} q_{5} q_{5 x}+\left(\omega^{2}-\omega_{x}^{2}\right) m_{f} q_{5} q_{5 x}=C_{1}+j D_{1}$

Where,

$$
C_{1}+j D_{1}=k_{s 1}\left[\left(y_{1 x}-q_{5 x}\right) q_{5}-\left(y_{1}-q_{5}\right) q_{5 x}\right]+j c_{s 1}\left[\left(y_{1 x}-q_{5 x}\right) \omega_{x} q_{5}-\left(y_{1}-q_{5}\right) \omega q_{5 x}\right]
$$

Equating real parts and also imaginary parts of eq. (25) results in two equations as follows:

$$
\begin{aligned}
& \left(\omega-\omega_{x}\right) c_{f} \operatorname{Imag}\left(q_{5} q_{5 x}\right)+\left(\omega^{2}-\omega_{x}{ }^{2}\right) m_{f} \operatorname{Real}\left(q_{5} q_{5 x}\right)=C_{1} \\
& -\left(\omega-\omega_{x}\right) c_{f} \operatorname{Real}\left(q_{5} q_{5 x}\right)+\left(\omega^{2}-\omega_{x}{ }^{2}\right) m_{f} \operatorname{Imag}\left(q_{5} q_{5 x}\right)=D_{1}
\end{aligned}
$$

Similarly, the equation of motion for the second support side results in similar expressions but with vibrations $q_{6}$ and $y_{2}$ instead of $q_{5}$ and $y_{1}$, and $C_{1}+j D_{1}$ replaced by a corresponding vector $C_{2}+j D_{2}$. Thus:

$$
\begin{aligned}
& \left(\omega-\omega_{x}\right) c_{f} \operatorname{Imag}\left(q_{6} q_{6 x}\right)+\left(\omega^{2}-\omega_{x}{ }^{2}\right) m_{f} \operatorname{Real}\left(q_{6} q_{6 x}\right)=C_{2} \\
& -\left(\omega-\omega_{x}\right) c_{f} \operatorname{Real}\left(q_{6} q_{6 x}\right)+\left(\omega^{2}-\omega_{x}{ }^{2}\right) m_{f} \operatorname{Imag}\left(q_{6} q_{6 x}\right)=D_{2}
\end{aligned}
$$

Where:

$$
C_{2}+j D_{2}=k_{s 2}\left[\left(y_{2 x}-q_{6 x}\right) q_{6}-\left(y_{2}-q_{6}\right) q_{6 x}\right]+j c_{s 2}\left[\left(y_{2 x}-q_{6 x}\right) \omega_{x} q_{6}-\left(y_{2}-q_{6}\right) \omega q_{6 x}\right]
$$

Equations (19) - (22) are now combined with eqs. (26) - (29) to become a set of 8 simultaneous equations with three unknown parameters, i.e. $k_{f}, c_{f}$ and $m_{f}$. These equations are reformulated into a matrix equation, and solve for the three unknown parameters by pseudo-inverse technique as shown in eq. (30), where $\mathbf{R}$ is an $8 \times 3$-coefficient matrix. Thus, 


$$
[\mathbf{R}]\left\{\begin{array}{l}
k_{f} \\
c_{f} \\
m_{f}
\end{array}\right\}=\left\{\begin{array}{l}
A_{1} \\
B_{1} \\
A_{2} \\
B_{2} \\
C_{1} \\
D_{1} \\
C_{2} \\
D_{2}
\end{array}\right\} ; \quad \text { Hence, }\left\{\begin{array}{l}
k_{f} \\
c_{f} \\
m_{f}
\end{array}\right\}=\left[\mathbf{R}^{\mathrm{T}} \mathbf{R}\right]^{-1} \mathbf{R}^{\mathrm{T}}\left\{\begin{array}{l}
A_{1} \\
B_{1} \\
A_{2} \\
B_{2} \\
C_{1} \\
D_{1} \\
C_{2} \\
D_{2}
\end{array}\right\}
$$

Where,

$$
\begin{aligned}
& {[\mathbf{R}]=\left[\begin{array}{ccc}
\left(\omega^{2}-\omega_{x}{ }^{2}\right) \operatorname{Real}\left(q_{5} q_{5 x}\right) & -\left(\omega^{2} \omega_{x}-\omega_{x}{ }^{2} \omega\right) \operatorname{Imag}\left(q_{5} q_{5 x}\right) & 0 \\
\left(\omega^{2}-\omega_{x}{ }^{2}\right) \operatorname{Imag}\left(q_{5} q_{5 x}\right) & \left(\omega^{2} \omega_{x}-\omega_{x}{ }^{2} \omega\right) \operatorname{Real}\left(q_{5} q_{5 x}\right) & 0 \\
\left(\omega^{2}-\omega_{x}{ }^{2}\right) \operatorname{Real}\left(q_{6} q_{6 x}\right) & -\left(\omega^{2} \omega_{x}-\omega_{x}{ }^{2} \omega\right) \operatorname{Imag}\left(q_{6} q_{6 x}\right) & 0 \\
\left(\omega^{2}-\omega_{x}{ }^{2}\right) \operatorname{Imag}\left(q_{6} q_{6 x}\right) & \left(\omega^{2} \omega_{x}-\omega_{x}{ }^{2} \omega\right) \operatorname{Real}\left(q_{6} q_{6 x}\right) & 0 \\
0 & \left(\omega-\omega_{x}\right) \operatorname{Imag}\left(q_{5} q_{5 x}\right) & \left(\omega^{2}-\omega_{x}{ }^{2}\right) \operatorname{Real}\left(q_{5} q_{5 x}\right) \\
0 & -\left(\omega-\omega_{x}\right) \operatorname{Real}\left(q_{5} q_{5 x}\right) & \left(\omega^{2}-\omega_{x}{ }^{2}\right) \operatorname{Imag}\left(q_{5} q_{5 x}\right) \\
0 & \left(\omega-\omega_{x}\right) \operatorname{Imag}\left(q_{6} q_{6 x}\right) & \left(\omega^{2}-\omega_{x}{ }^{2}\right) \operatorname{Real}\left(q_{6} q_{6 x}\right) \\
0 & -\left(\omega-\omega_{x}\right) \operatorname{Real}\left(q_{6} q_{6 x}\right) & \left(\omega^{2}-\omega_{x}{ }^{2}\right) \operatorname{Imag}\left(q_{6} q_{6 x}\right)
\end{array}\right]} \\
& A_{1}=\operatorname{Real}\left(\left(k_{s 1}+j \omega_{x} c_{s 1}\right)\left(y_{1 x}-q_{5 x}\right) \omega^{2} q_{5}-\left(k_{s 1}+j \omega c_{s 1}\right)\left(y_{1}-q_{5}\right) \omega_{x}^{2} q_{5 x}\right) \\
& B_{1}=\operatorname{Imag}\left(\left(k_{s 1}+j \omega_{x} c_{s 1}\right)\left(y_{1 x}-q_{5 x}\right) \omega^{2} q_{5}-\left(k_{s 1}+j \omega c_{s 1}\right)\left(y_{1}-q_{5}\right) \omega_{x}^{2} q_{5 x}\right) \\
& A_{2}=\operatorname{Real}\left(\left(k_{s 2}+j \omega_{x} c_{s 2}\right)\left(y_{2 x}-q_{6 x}\right) \omega^{2} q_{6}-\left(k_{s 2}+j \omega c_{s 2}\right)\left(y_{2}-q_{6}\right) \omega_{x}^{2} q_{6 x}\right) \\
& B_{2}=\operatorname{Imag}\left(\left(k_{s 2}+j \omega_{x} c_{s 2}\right)\left(y_{2 x}-q_{6 x}\right) \omega^{2} q_{6}-\left(k_{s 2}+j \omega c_{s 2}\right)\left(y_{2}-q_{6}\right) \omega_{x}^{2} q_{6 x}\right) \\
& C_{1}=\operatorname{Real}\left(k_{s 1}\left[\left(y_{1 x}-q_{5 x}\right) q_{5}-\left(y_{1}-q_{5}\right) q_{5 x}\right]+j c_{s 1}\left[\left(y_{1 x}-q_{5 x}\right) \omega_{x} q_{5}-\left(y_{1}-q_{5}\right) \omega q_{5 x}\right]\right) \\
& D_{1}=\operatorname{Imag}\left(k_{s 1}\left[\left(y_{1 x}-q_{5 x}\right) q_{5}-\left(y_{1}-q_{5}\right) q_{5 x}\right]+j c_{s 1}\left[\left(y_{1 x}-q_{5 x}\right) \omega_{x} q_{5}-\left(y_{1}-q_{5}\right) \omega q_{5 x}\right]\right) \\
& C_{2}=\operatorname{Real}\left(k_{s 2}\left[\left(y_{2 x}-q_{6 x}\right) q_{6}-\left(y_{2}-q_{6}\right) q_{6 x}\right]+j c_{s 2}\left[\left(y_{2 x}-q_{6 x}\right) \omega_{x} q_{6}-\left(y_{2}-q_{6}\right) \omega q_{6 x}\right]\right) \\
& D_{2}=\operatorname{Imag}\left(k_{s 2}\left[\left(y_{2 x}-q_{6 x}\right) q_{6}-\left(y_{2}-q_{6}\right) q_{6 x}\right]+j c_{s 2}\left[\left(y_{2 x}-q_{6 x}\right) \omega_{x} q_{6}-\left(y_{2}-q_{6}\right) \omega q_{6 x}\right]\right)
\end{aligned}
$$

\subsection{MEASURING ROTOR VIBRATIONS}

The identification of unbalanced forces and the parameters of the mountings and foundation from eq. (14) and eq. (30), require measurements of vibrations of the rotor and the machine structure. While measurements on the machine structure can be a straight forward business, measurements on the rotor needs further clarification. In some machines, the centre of gravity of the rotor may not be accessible for measurement while the machine is in operation because accessing the rotor may mean dismounting it. In this case, assuming the rotor is rigid, measurements of linear and rotational degrees-of-freedom at the rotor centre of gravity, $q_{1}(t)$ and $q_{2}(t)$ respectively, can be established by measurements on the rotor shaft at the bearings. 


$$
q_{1}(t)=\frac{x_{2}}{x_{1}+x_{2}} y_{r 1}(t)+\frac{x_{1}}{x_{1}+x_{2}} y_{r 2}(t)
$$

However, as the rotor is rotating, measurements $y_{r 1}(t)$ and $y_{r 2}(t)$ cannot be done using a contacting transducer. A non contacting transducer, eg. a proximity probe, have to be employed. For a rotor supported on rolling

$$
\begin{aligned}
& q_{1}(t)=\frac{x_{2}}{x_{1}+x_{2}} y_{B 1}(t)+\frac{x_{1}}{x_{1}+x_{2}} y_{B 2}(t) \\
& q_{2}(t)=\frac{y_{B 1}(t)-y_{B 2}(t)}{x_{1}+x_{2}}
\end{aligned}
$$

Where $y_{B 1}(t)$ and $y_{B 2}(t)$ are vibrations of the bearing housings, typically measured by a contacting transducer. This simplification may not apply to rotors with journal bearing supports due to the possibility of ample movement of the rotor shaft within the bearings.

\subsection{NUMERICAL SIMULATION}

The theory presented in Section 2 for the identification of unbalanced forces, mounting parameters and foundation parameters of rotating machines was verified by a numerical example.

\section{EXAMPLE}

A rotor of mass $50 \mathrm{~kg}$ is supported by two bearings at a span of $600 \mathrm{~mm}$. The machine structure, excluding the rotor, is of mass 200 $\mathrm{kg}$. The machine is supported by mountings also at a span of $600 \mathrm{~mm}$. The foundation was simulated to be flexible, with an effective mass of $400 \mathrm{~kg}$, effective stiffness of $4.0 \mathrm{MN} / \mathrm{m}$ and effective damping of $400 \mathrm{Ns} / \mathrm{m}$. The machine system is shown in Fig. 2. Rotor unbalance equivalent to a centrifugal force of $1000 \mathrm{~N}$ and moment $500 \mathrm{Nm}$ acting at rotor centre of gravity was assumed. The centre of gravity of the rotor is at mid-span between the bearings, while the centre of gravity of the machine structure is at the middle between the mounting locations. Complete data of the simulated system is shown in Table 1. The simulated data was used to compute simulated vibration responses of the machine and the foundation of a 6 DOF model like the one shown in Fig. 1,

\begin{tabular}{|c|c|c|c|c|c|}
\hline & Mass $(\mathrm{kg})$ & $\begin{array}{c}\text { Moment of } \\
\text { Inertia }\left(\mathrm{kgm}^{2}\right)\end{array}$ & Stiffness $(\mathrm{N} / \mathrm{m})$ & Damping $(\mathrm{Ns} / \mathrm{m})$ & Load (N) \\
\hline Rotor $(\mathrm{n}=1500 \mathrm{rpm})$ & 50 & 0.56 & - & - & - \\
\hline Bearing 1 & - & & $0.50 \times 10^{6}$ & 100 & - \\
\hline Bearing 2 & - & & $0.25 \times 10^{6}$ & 100 & - \\
\hline Unbalanced Force & - & & - & - & 1000 \\
\hline $\begin{array}{l}\text { Unbalanced } \\
\text { Moment }\end{array}$ & - & & - & - & 500 \\
\hline Machine structure & 200 & 24 & - & - & - \\
\hline Support 1 & - & & $2.0 \times 10^{6}$ & 200 & - \\
\hline Support 2 & - & & $2.5 \times 10^{6}$ & 300 & - \\
\hline Foundation & 400 & & $4.0 \times 10^{6}$ & 400 & - \\
\hline Distances (mm) & \multicolumn{5}{|c|}{$\mathrm{x}_{1}=\mathrm{x}_{2}=\mathrm{x}_{3}=\mathrm{x}_{4}=\mathrm{x}_{5}=\mathrm{x}_{6}=300 \mathrm{~mm}$} \\
\hline & & & & & \\
\hline
\end{tabular}
using MATLAB application package.

Table 1: Simulated Data of Rotating Machine 
(i) Identification of Unbalanced Forces and Mounting Parameters

Vibration responses of the 6 DOF machine system excited by the centrifugal unbalanced force and unbalanced moment was computed. An unbalanced mass of $\Delta \mathrm{m}=100 \mathrm{~g}$ at a radial position of $200 \mathrm{~mm}$ but $60^{\circ}$ ahead of the unbalanced force, was simulated to be attached to the rotor at an axial distance $\mathrm{x}=0.5 \mathrm{~m}$ from the rotor centre of gravity away from bearing 1 . The unbalanced mass contributed to unbalanced force and equivalent unbalanced moment at the rotor centre of gravity, given by
$\Delta F_{u}=\Delta m \omega^{2} \times e \quad$ and $\quad \Delta M_{u}=\Delta m \omega^{2} \times e x$, where $e$ is the radial position vector of the unbalanced mass. Vibration responses due to the combined presence of this unbalanced mass and the original unbalanced force and moment were computed. The unbalanced mass was then moved to a different angular position of $240^{\circ}$ and new vibration responses computed. Table 2 shows the simulated vibration responses for the translational DOF of the system before and after adding unbalanced masses to the rotor.

Table 2: Simulated Vibration Responses Before and After Adding Mass to the Rotor

\begin{tabular}{|c|c|c|c|}
\hline Degree-of-freedom & $\begin{array}{c}\text { Response in } \mathrm{mm} \\
(\Delta \mathrm{m}=0)\end{array}$ & $\begin{array}{l}\text { Response in } \mathrm{mm} \\
\left(\Delta \mathrm{m}=200 \mathrm{~g} \text { at } 60^{\circ}\right)\end{array}$ & $\begin{array}{c}\text { Response in } \mathrm{mm} \\
\left(\Delta \mathrm{m}=200 \mathrm{~g} \text { at } 240^{\circ}\right)\end{array}$ \\
\hline$q_{1}$ & $-1.394+j 2.4388$ & $-0.257+j 1.1652$ & $-2.0662+j 1.2561$ \\
\hline$q_{3}$ & $0.5673-\mathrm{j} 3.2189$ & $-1.5075-\mathrm{j} 2.8047$ & $1.8030-\mathrm{j} 2.1822$ \\
\hline$q_{5}$ & $-1.3897+j 5.8794$ & $2.3305+j 5.009$ & $-3.5595+j 3.8348$ \\
\hline$q_{6}$ & $1.0046-j 3.6899$ & $-1.2435-j 2.9575$ & $2.3337-\mathrm{j} 2.3501$ \\
\hline$y_{1}=q_{3}+x_{5} q_{4}$ & $2.2314-j 11.4761$ & $-4.8945-j 9.5055$ & $6.5853-j 7.6908$ \\
\hline$y_{2}=q_{3}-x_{6} q_{4}$ & $-1.0968+j 5.0383$ & $1.8796+j 3.8961$ & $-2.9794+j 3.3264$ \\
\hline
\end{tabular}

The simulated response data in Table 2 and the system data in Table 1 were used to identify unbalanced force, moment and mounting parameters using eq. (14) and resulted in the following:

$$
\left\{\begin{array}{c}
k_{s 1}+j \omega c_{s 1} \\
k_{s 2}+j \omega c_{s 2} \\
F_{u} \\
M_{u}
\end{array}\right\}=\left\{\begin{array}{c}
2.0 \times 10^{3}+j 314 \\
2.5 \times 10^{3}+j 471 \\
1.0 \\
0.5
\end{array}\right\} \times 10^{3}
$$

Hence

$$
\begin{array}{ll}
\mathrm{k}_{\mathrm{s} 1}=2.0 \times 10^{6} \mathrm{~N} / \mathrm{m}, & \mathrm{k}_{\mathrm{s} 2}=2.5 \times 10^{6} \mathrm{~N} / \mathrm{m} \\
\mathrm{c}_{\mathrm{s} 1}=200 \mathrm{Ns} / \mathrm{m}, & \mathrm{c}_{\mathrm{s} 2}=300 \mathrm{Ns} / \mathrm{m} \\
\mathrm{F}_{\mathrm{u}}=1000 \mathrm{~N}, & \mathrm{M}_{\mathrm{u}}=500 \mathrm{~N}
\end{array}
$$

Unbalanced force, moment and machine mounting parameters are exactly identified.

\section{(ii) Identification of Foundation Parameters}

The system was then simulated at a different rotor speed of $2500 \mathrm{rpm}$. Unbalanced force and moment are proportional to the square of the speed. Therefore, simulated unbalanced force and moment were proportionately adjusted to the new speed. Vibration responses due to the unbalances at the new speed were evaluated as shown in Table 3. 
Table 3: Simulated Vibration Responses at New Rotor Speed $(n=2500 \mathrm{rpm})$

\begin{tabular}{|c|c|}
\hline Degree-of-freedom & $\begin{array}{c}\text { Response in } \mathbf{~} \mathbf{m} \\
(\mathbf{\Delta}=\mathbf{m})\end{array}$ \\
\hline$q_{1 \mathrm{x}}$ & $0.0888-\mathrm{j} 0.0621$ \\
\hline$q_{3 \mathrm{x}}$ & $-0.1319+\mathrm{j} 0.0219$ \\
\hline$q_{5 \mathrm{x}}$ & $0.0364-\mathrm{j} 0.0024$ \\
\hline$q_{6 \mathrm{x}}$ & $-0.0149-\mathrm{j} 0.0013$ \\
\hline$y_{1 x}=q_{3 x}+x_{5} q_{4 x}$ & $-0.3887+\mathrm{j} 0.0384$ \\
\hline$y_{2 x}=q_{3 x}-x_{6} q_{4 x}$ & $0.1249+\mathrm{j} 0.0055$ \\
\hline
\end{tabular}

The new and original vibrations, together with identified mounting parameters $\mathrm{k}_{\mathrm{s} 1}, \mathrm{k}_{\mathrm{s} 2}, \mathrm{c}_{\mathrm{s} 1}$ and $\mathrm{c}_{\mathrm{s} 2}$ were used to identify foundation parameters using eq. (30) and resulted in:

$$
\left\{\begin{array}{l}
k_{f} \\
c_{f} \\
m_{f}
\end{array}\right\}=\left\{\begin{array}{c}
4.0 \times 10^{6} \\
400 \\
400
\end{array}\right\}
$$

Therefore, the foundation parameters have been exactly identified. With the identified parameters, forces transmitted to the foundation may now be estimated as follows:

Force transmitted through mounting 1: $\quad F_{T}=\left(k_{f}+j \omega c_{f}\right)\left(q_{5}-y_{1}\right)$

Force transmitted through mounting 2: $\quad F_{T}=\left(k_{f}+j \omega c_{f}\right)\left(q_{6}-y_{2}\right)$

Forces transmitted to the foundation at the two speeds are shown in Table 4.

Table 4: Force Transmitted to The Foundation

\begin{tabular}{|l|l|l|l|}
\hline Speed & Location & Transmitted Force (N) & Force Amplitude (N) \\
\hline \multirow{2}{*}{500} & Through mounting 1 & $-9,688+\mathrm{j} 27,684$ & 29,331 \\
\cline { 2 - 4 } & Through mounting 2 & $-612+\mathrm{j} 1,673$ & 1,782 \\
\hline \multirow{2}{*}{2500} & Through mounting 1 & $852-\mathrm{j} 59$ & 854 \\
\cline { 2 - 4 } & Through mounting 2 & $-279-\mathrm{j} 21$ & 280 \\
\hline
\end{tabular}

\subsection{CONCLUSIONS}

A technique has been presented to identify unbalanced forces and foundation parameters of rotating machines with rigid rotors, from vibration measurements. The technique uses vibrations measured on a rotating rotor, using non contacting transducers, or on rotor bearing housings using contacting transducers, vibrations measured on the machine structure and the vibrations measured on the foundation.

\section{REFERENCES}

[1] Lees, A.W. (1988), "The Least Square Method Applied to Investigating Rotor/Foundation Interactions". IMechE Conference, Vibrations in Rotating Machinery, Edinburgh UK, Paper No. C366/065.
The technique has been verified using simulated data for a two bearings rotor. The technique does not require prior knowledge of the unbalanced forces or bearing stiffness. While the technique has performed successfully with simulated data, further work is necessary in order to account for the real situation encountered in practical set-ups. Practical measurements are always contaminated with measurement errors, some of which are random but others may be systematic.

[2] Lees, A.W. and Friswell, M.I. (1996), "Estimation of Forces Exerted on Machine Foundations". Proceedings of the $1^{\text {st }}$ International Conference on Identification in Engineering Systems". Swansea UK, pp. 793-803.

[3] Odiara, E.A. and Ewins, D.J. (1992), "Parameters Identification for NonLinear Rotor-Stator Systems: The 
Volterra/Wiener Based Approach". IMechE Conference, Vibrations in Rotating Machinery, Bath UK, Paper No. C432/111.

[4] Sinha, J.K., Lees, A.W. and Friswell M.I. (2002). The Estimation of Foundation Parameters of Flexible Machines. Proceedings of $3^{\text {rd }}$ International Conference on
Identification in Engineering Systems. Swansea UK, pp. 300-310.

[5] Zannetta, G.A. (1992), "Identification Methods in the Dynamics of Turbogenerator Rotors". IMechE Conference, Vibrations in Rotating Machinery, Bath UK, Paper No. C432/092 